\title{
Alkol-Madde Bağımlılarının Kan Parametrelerinin Kıyaslanması
}

\author{
Müberra KULU ${ }^{1}$
}

\begin{abstract}
Özet: Biz çalışmamızda alkol/madde kullanım bozukluğu tanısı ile tedavi alan hastaların bazı labaratuar parametrelerini incelemeyi amaçladık. 106 alkol kullanım bozukluğu (AKB), 120 madde kullanım bozukluğu (MKB) ve sağlıklı kontrol grubunun dosyaları geriye dönük olarak taranmıştır. Tüm katılımcıların; AST, ALT, TSH (Tiroit Stimülan Hormon), FT3, FT4, B12, Folik asit, Ferritin, tam kan sayımı gibi biyokimyasal değerleri incelenmiştir. Hemotokrit değeri MKB kişilerin kontrol grubundan yüksek olarak hesaplandı $(p=0.013)$. MCV değeri ise; hastalarda kontrollere göre yüksekti $(\mathrm{p}=0.000 ; \mathrm{p}=0.000)$. AKB hastalarında platelet değeri diğer iki gruptan düşüktü $(p=0.000 ; p=0.001)$; karaciğer enzimleri ise yüksekti $(p<0.05)$. Vitamin $B 12$ ve folik asit değerleri için ise AKB sağlıklı kontrol ve MKB tanılı kişilerden yüksek olarak bulundu ( $\mathrm{p}=0.000)$. MKB hastalarının ferritin değeri diğer iki gruptan düşüktü $(\mathrm{p}=0.000)$. $\mathrm{AKB}$ ve $\mathrm{MKB}$ tanılı kişilerin tedavileri planlanırken; labaratuar parametrelerinde olan değişiklikler göz önüne alınmalı ve tedavi bu şekilde planlanmalıdır.
\end{abstract}

Anahtar kelimeler: Alkol kullanım bozukluğu, madde kullanım bozukluğu, biyokimyasal parametreler, karaciğer enzimleri.

\section{Comparison of Blood Parameters of Alcohol/Substance Addicts}

\begin{abstract}
We aimed to investigate some laboratory parameters of patients treated with alcohol/substance use disorder. The records of 106 alcohol use disorders (AUD), 120 substance use disorders (SUD) and healthy control group were retrospectively reviewed.All the participants; AST, ALT, TSH, FT3, FT4, B12, Folic acid, Ferritin, whole blood counts were investigated. Hematocrit value of patients with SUD was higher than the control group $(\mathrm{p}=0.013)$.Patients had higher MCV values than controls. Platelet levels were lower in patients with AUD than in the other two groups $(\mathrm{p}=0.000 ; \mathrm{p}=0.001)$ and liver enzymes were high. Vitamin B12 and folic acid levels of AUD patients were higher than the other two groups $(\mathrm{p}=0.000)$. The ferritin levels of the SUD patients were lower than the other two groups $(\mathrm{p}=0.000)$. While planning the treatment of patients; changes in laboratory parameters should be considered and treatment should be planned in this way.
\end{abstract}

Key Words: Alcohol use disorder, substance use disorder, biochemical parameters, liver enzymes.

${ }^{1}$ Uzm. Dr., Tokat Ruh Sağlığı ve Hastalıkları Hastanesi, Tokat

Address of correspondence/ Yazışma adresi: Uzm. Dr. Müberra Kulu, Tokat Ruh Sağlığı ve Hastalıkları Hastanesi, Tokat, Psikiyatri E-mail: muberrakilic@yahoo.com

Date of Received/Geliş Tarihi: 15.10.2019, Date of Revision/Düzeltme Tarihi: 02.11.2019, Date of Acceptance/Kabul Tarihi: 05.11.2019

Citing/ Referans Gösterimi: Kulu, M. (2019). Alkol-madde bağımlılarının kan parametrelerinin kıyaslanması. Kıbrls Türk Psikiyatri ve Psikoloji Dergisi, 1(Özel Sayı.1): 47-49 doi:10.35365/ctjpp.19.special1.13 


\section{Giriş}

Alkol/Madde Kullanım Bozukluğu (AMKB); alınan tüm önlemlere rağmen tüm dünyada olduğu gibi ülkemizde de giderek artan bir sorun olmaya devam etmektedir. Tüm dünyada toplam 200 milyon kişi son bir yılda yasa dış1 madde kullandığ 1 tespit edilmiştir (Sarra, Hedden, Kennet, Lipari, Medley, Tice, 2015). AMKB; yaşamın her alanını etkileyebilen bir rahatsızlıktır. Kişinin ruhsal ve bedensel sağlığını, güvenliğini ve yaşam kalitesini bozmaktadır ve bu durumun da topluma maliyeti oldukça yüksek olmaktadır (Bouchery, Harwood, Sacks, Simon ve Brewer, 2011; Konkolÿ ve Hodgins, 2016).

AMKB olan bireylerde beslenme düzeninin değişmesi ile yanlış beslenme uygulamaları görülmektedir. Bağımlılık yapan maddelerin kendi farmakolojik özellikleri, kişinin değişen beslenme düzeni ile primer vesekonder malnütrisyon ortaya çıkabilmektedir (Lieber, 2003). Alkol ve madde kullanımının; gastrointestinal bölgede oluşturduğuhasar sonucu gelişen iştah kaybı, bulant1, kusma, ishal, sindirim ve emilim bozuklukları olabilmektedir (Thorley, Porter, Fleming, Jones, Kesten, Marques, et al, 2015). Alkol ve madde kullanımına bağlı ortaya çıkan tıbbi komplikasyonlar; ülkelerin ekonomik ve sosyal durumlarından bağımsız olarak büyük tıbbi harcamalara yol açmaktadır (Bradley, 1992).

AMKB'na bağlikomplikasyonların labaratuar parametrelerindeki değişikliklerden kaynaklanabileceği düşüncesi ile çalışmamızı planladık.

\section{Yöntem}

DSM-V kriterlerine göre; 106 Alkol Kullanım Bozukluğu (AKB) ve 120 Madde Kullanım Bozukluğu (MKB) tanılı hastanın dosyaları inceledi. Hastaların tedavi öncesi, yatışının ilk günü alınan açlık glukoz, üre, kreatinin, AST, ALT, TSH, FT3, FT4, B12, Folat, lökosit, eritrosit,trombosit, hemoglobin, hematokrit ve MCV gibi biyokimyasal değerleri incelendi. Ek olarak 60 kişi sağlıklı kontrol grubu olarak çalışmamıza dahil edildi. Sağlıklı kontroller; psikiyatri polikliniği ve askeri sağlık kurulunda muayene edilip tanı ölçütlerini karşılayacak bir hastalığı olmayan kişiler arasından seçildi ve bu kişilerinde dosyaları üzerinden inceleme yapıldı.

Nicel değişkenler arasında ilişki olup olmadığı değerlendirilirken; İki Ortalama Arasındaki Farkın Önemlilik testi kullanılmıștır. p değerleri 0.05 'den küçük hesaplandığında istatistiksel olarak anlamlı kabul edilmiştir.

\section{Bulgular}

Tüm katılımcılar erkekti; yaş ortalaması AKB hastalarının $42.63 \pm 12,88$, MKB hastalarının 25.06 \pm 9.12 , kontrol grubunun ise $28.01 \pm 10.12$ idi. AMKB tanıl hastaların kan değerleri hastaneye yattıkları ilk gün alınan kan örneklerinden bakılmıştır. Sağlıklı kontrol grubu ise sistem incelemesinde tanı almış psikiyatri hastalığı ve hali hazırda tedavi alımı olmayan kişiler arasından seçilmiştir. Tam kan sayımı, karaciğer enzimleri, böbrek fonksiyonları, Vitamin B 12, folik asit, ferritin incelenen labaratuar parametreleridir. Tam kan sayımı değerlendirilmesinde ise; beyaz küre, hemoglobin değerleri farklı değildi. Fakat hemotokrit değeri MKB tanılı kişilerin kontrol grubuna kıyasla yüksek olarak hesaplandı $(\mathrm{p}=0.013)$. AKB ve MKB tanılı hastaların hemotokrit değerleri arasında istatistiksel farklilik yoktur $(\mathrm{p}=0.628)$. Platelet; AKB hem MKB olan gruptan hem de kontrol grubundan düşüktü (AKB tanılı hastalar ile MKB olan grup ve kontrol grubu kıyasta siras1 ile $\mathrm{p}$ değerleri $\mathrm{p}=0.000 ; \mathrm{p}=0.001)$. $\mathrm{MCH}$ ve $\mathrm{MCHC}$ değerleri arasında her iki hasta grubunda da farklılık yoktu. MCV değeri ise; AKB ve MKB tanılı hastaların sağlıklı kontrollerden yüksek olarak tespit edildi $(\mathrm{p}<0.05)$.

Karaciğer enzimleri için AKB tanılı hastaların hem sağlıklı kontrollerden hem de MKB tanılı hastalardan yüksek olarak saptandı. Sağlıklı kontroller ile kıyaslanınca AKB tanılı hastaların; AST değeri için $\mathrm{p}=0.033$; ALT değeri için ise $\mathrm{p}=0.040$ olarak bulundu. Tiroid fonksiyon değerleri ne AKB ne de MKB tanılı hastaların sağlıklı kontrollerden farklı değildi $(p>0.05)$. Vitamin B12, folik asit değerleri hasta grubunda yüksekti. Ferritin değeri ise düşük olarak hesapland1.

\section{Tartıșma}

Biz çalışmamızda; AKB ve MKB tanılı hastaların bazı laboratuvar parametrelerini hem sağlıklı kontrollerle hem de birbiri ile kıyasladık. Bazı değerlerin hem sağlıklı kontrollerden hem de bağımlı gruplar arasında farklılık gösterdiğini tespit ettik. Çalışmamız geriye dönük olarak planlanmıştır ve dosya üstünden veriler taranmıştır. Literatürde AMKB tanılı hastaların hematolojik parametreleri ile ilgili sonuçlar tartışmalıdır. Opioid bağımlısı hastalarla yapılan bir çalışmada; hematokrit seviyesi yüksek olarak tespit edilmiştir (Çatak, 2017). Başka çalıșmalarda ise hem hemoglobin, hem de hemotokrit düzeyleri düşük bulunmuştur (Aghaee-Afshar, Khazaeli, Behnam, et al., 2008; Haghpanah, Afarinesh, Divsalar, 2010). Literatürde kan trombosit düzeylerinin opioid kullanımından etkilenebileceği gösterilmiştir (Çatak, 2017).Morfin uygulanan ratlarda yapılan bir çalışmada; hemoglobin ve trombosit düzeylerinin düşük, trombosit sayıs1 ise yüksek bulunmuştur (Othman ve Amin, 2012). Opioid bağımlısı hastalarda yapılan başka bir çalışmada; trombosit düzeylerinin yüksek olduğu saptanmıştır (Çatak, 2017). Bizim sonuçlarımızda ise; trombosit düzeyleriAKB tanılı hastaların hem sağlıklı kontroller hem de MKB tanılı hastalara göre düşük olarak bulunurken; MKB tanılı hastalarda anlamlı bir farklılık olmadığı görüldü. Ortalama eritrosit volümü $(\mathrm{MCH})$ ve Ortalama eritrosit hemoglobin konsantrasyonu (MCHC) değerleri ise hasta grubunda farklılık göstermedi. Ortalama hücre hacmi (MCV) değeri hem AKB hem de MKB tanılı hastalarda sağlıklı kontrol grubuna kıyasla anlamlı düzeyde yüksekti. AKB tanılı hastaların geriye dönük labaratuvar sonuçlarının incelendiğ bir çalışmada; MCV düzeylerinin farklı olmadığ 1 görülmüștür (Göğcegöz-Gül, Kartalc1, Karlıdağ ve Cumurcu, 2012). Literatürde bazı çalışmalarda madde bağımlıs1 kişilerde MCV düzeylerinin düşüklüğü gösterilmiştir (Çatak, 2017;Aghaee-Afshar, Khazaeli, Behnam, et al., 2008).

Hem hipotirodi hem de hipertiroidide psikiyatrik hastalıkların sıklığı çalışmalarda bildirilmiştir. Unutkanlık, 
konsantrasyon güçlüğü gibi spesifik olmayan belirtilerden majör depresif bozukluk ve psikotik bozukluk gibi DSM-V tanı kriterlerini karşılayan geniş yelpazede pek çok hastalık ortaya çıkabilmektedir (Göğcegöz-Gül, Kartalcı, Karlıdağ ve Cumurcu, 2012; Eren, Cüre, İnanl, Kutlucan, Köroğlu ve Tamer, 2006). Bizim sonuçlarımızda; tiroid fonksiyonları hasta gruplarında anlamlı bir farklılık göstermedi. Elde ettiğimiz bu sonuç literatür ile benzer nitelikte olmuștur. Alkol bağımlısı erkek cinsiyette hastalar ile yürütülen bir çalışmada; içinde tiroid fonksiyonları da bulunan biyokimyasal parametrelerin hasta grubunda farkl1 olmadığı tespit edilmiştir (Göğcegöz-Gül, Kartalc1, Karlıdağ ve Cumurcu, 2012).

Karaciğerde AKB'na bağlı olarak; karaciğer yağlanması, alkolik hepatit ve siroz gibi hastalıklar meydana gelebilir. $\mathrm{Bu}$ hastalıkların hepsinde de karaciğer enzimleri normalden yüksek sınırlardadır (Salış ve Akpınar, 2011). Literatürde yapılan çalışmalarda karaciğerde tanı almış herhangi bir hastalık olmasa da enzimlerin normalden yüksek olduğu bildirilmiştir (Salış ve Akpınar, 2011; Akpınar, Çevik ve Bağcığlu, 2014; Mırsal, Özkan-Pektaş, Kalyoncu ve Beyazyürek, 2002). Bizim sonuçlarımızda da bu çalışmalara benzer nitelikte; AKB tanılı hastaların karaciğer enzimlerinin yüksek olduğu tespit edilmiştir.
Son olarak metabolizmaları birbiriyle ilişkili olan Vitamin B12, folik asit ve ferritin; merkezi sinir sistemi için gerekli olan elementlerdir. B12 vitamini ve folik asit eksikliği serumda homosistein seviyelerinin yükselmesine neden olur. $\mathrm{Bu}$ durumun da; bozulmuş bilişsel fonksiyonlar, demans, ataksi, nöropati gibi nörolojik bozuklukların patogenezine katkıda bulunduğunu gösteren çok sayıda çalışma vardır (Özyurtlu, Örün, Sıvacı, Duran, Demiralay, Türkeş, et al., 2015).Hatta kan tablosu normal iken yani anemi gelişmeden sadece nörobilişsel fonksiyonlarda bozulma olduğu gösterilmiştir (Wlodarczyk, Brodaty ve Hawthorne, 2004). AMKB tanili hastalar normal olarak görünse de; nöropsikolojik değerlendirmelerde; dikkat, amaca yönelik motor hareket, planlama gibi pek çok işlevden sorumlu olan frontal alan ile ilgili bozuklukları olduğu gösterilmiştir(Vik, Celluci, Jarchow ve Hedt, 2004). Bizim sonuçlarımızda ise; AKB tanılı hastaların vitamin B 12 ve folik asit düzeyleri yüksek iken; MKB tanılı hastalarda ferritin düzeyleri düşük idi.AKB tanılı hastalarda vitamin B12 ve folik asit düzeylerinin yüksekliği eski aldıkları vitamin tedavilerine bağlanmıștır. Uzun süreli alkol kullanımı olan kişilere farmakolojik tedavilerinin yanına eklenen vitamin komplekslerinin bu sonuçta etkili olabileceği düşünülmüştür.

\section{Kaynaklar}

Sarra, L., Hedden, J., Kennet, R., Lipari, G., Medley, P.T, Tice, R.,T.I. (2015). Behavioral Health Trends in the United States: Results from the 2014 National Survey on Drug Use and Health. United States: Rocville MD/HHS Publication.

Bouchery, E. E., Harwood, H. J., Sacks, J. J., Simon, C. J., \& Brewer, R. D. (2011). Economic costs of excessive alcohol consumption in the US, 2006. American journal of preventive medicine, 41(5), 516-524.

Konkolÿ Thege, B., Hodgins, D. C., \& Wild, T. C. (2016). Cooccurring substance-related and behavioral addiction problems: A person-centered, lay epidemiology approach. Journal of Behavioral Addictions, 5(4), 614-622.

Lieber, C. S. (2003). Relationships between nutrition, alcohol use, and liver disease. Alcohol Research and Health, 27, 220-231.

Thorley, H., Porter, K., Fleming, C., Jones, T., Kesten, J., Marques, E., ... \& Savović, J. (2015). Interventions for preventing or treating malnutrition in problem drinkers who are homeless or vulnerably housed: protocol for a systematic review. Systematic reviews, 4(1), 131.

Bradley, K. A. (1994). The primary care practitioner's role in the prevention and management of alcohol problems. Alcohol Health \& Research World, 18(2), 97-105.

Çatak, Z. (2017). Opioid Bağımlısı Erkek Hastalarda Bazı Hematolojik Parametrelerin Değerlendirilmesi. Firat Üniversitesi Sağllk Bilimleri Tıp Dergisi, 31(2): 79-82.

Aghaee-Afshar, M., Khazaeli, P., Behnam, B., Rezazadehkermani, M., \& Ashraf-Ganjooei, N. (2008). Presence of lead in opium. Arch Iran Med, 11(5), 553-4.

Haghpanah, T., Afarinesh, M., \& Divsalar, K. (2010). A review on hematological factors in opioid-dependent people (opium and heroin) after the withdrawal period. Addiction \& health, 2(1-2), 9.

Othman, G. Q., \& Amin, Y. K. (2012). Oxidative stress and some cellular blood variables in morphine addicted female rats. Medical Journal of Tikrit, 18(182), 134-142.
11. Göğcegöz-Gül, I., Kartalcı, Ş., Karlıdağ, R., \& Cumurcu, B. E. (2012). Graves Hastalığına Bağlı Gelişen Psikotik Bozukluk: Bir Olgu Sunumu. Archives of Neuropsychiatry/Noropsikiatri Arsivi, 49(4).

Eren, İ., Cüre, E., İnanlı, İ. Ç., Kutlucan, A., Köroğlu, B. K., \& Tamer, M. N. (2006). Klinik ve Subklinik Hipotiroidide Psikiyatrik Belirti Düzeyi ve Psikiyatrik Belirtilerin Tiroid Hormon Düzeyleri İle İlişkisi. Klinik Psikiyatri, 9, 131-137.

Salış, O., \& Akpınar, A. (2011). Alkol bağımlılığında Gama Glutamin Transferaz (GGT) düzeyinin kan biyokimyasal testleri ve klinik özellikler ile bağlantısı. Sağlık Bilimleri Enstitüsü Dergisi, 2; 2.

Akpınar, A., Çevik, M., \& Bağcıŏglu, E. (2014). Erkek Alkol Bağımlılığında Nüks ile Biyokimyasal Etmenler Arasındaki İlişki Var Midır?. Kocatepe Tip Dergisi, 15(3), 238-245.

Mırsal, H., Özkan Pektaş, D., Kalyoncu, A., \& Beyazyürek, M. (2002). Alkol bağımlılarında karaciğer fonksiyon testleri ve sosyodemografik-klinik özellikler arasındaki ilişki. Bağımlılık Dergisi, 3(1).

Özyurtlu, D., Örün, M. O., Sıvacı, A. Ö., Duran, S., Demiralay, A., Türkeş, N., ... \& Bakar, M. B12 Vitamini ve Folik Asit Eksikliğinin Bilişsel Fonksiyonlar Üzerine Etkisinin Değerlendirilmesi. Uludağ Üniversitesi Tip Fakültesi Dergisi, 41(1), 5-9.

Wlodarczyk, J. H., Brodaty, H., \& Hawthorne, G. (2004). The relationship between quality of life, Mini-Mental State Examination, and the Instrumental Activities of Daily Living in patients with Alzheimer's disease. Archives of gerontology and geriatrics, 39(1), 25-33.

Vik, P. W., Cellucci, T., Jarchow, A., \& Hedt, J. (2004). Cognitive impairment in substance abuse. Psychiatric Clinics of North America, 27; 97-109. 